\title{
Perspectivas e análises do processo formativo de educadoras no projeto tecendo a cidadania no campo ${ }^{i}$
}

\author{
Alisson Silva da Costa ${ }^{1}$, Cláudia Valéria de Assis Dansa ${ }^{2}$, Nathália Barros Ramos ${ }^{3}$ \\ 1, 2, 3 Universidade de Brasília - UnB. Faculdade de Educação. Asa Norte. Campus Universitário Darcy Ribeiro. Brasília - DF. \\ Brasil. \\ Autor para correspondência/Author for correspondence: alisson.dec@gmail.com
}

\begin{abstract}
RESUMO. Este artigo possui como problema de pesquisa a Educação do Campo e a formação dos professores que nela atuam - por meio da análise e discussão do trabalho pedagógico de educadoras participantes do Programa Nacional de Educação na Reforma Agrária (PRONERA), desenvolvido no âmbito da Educação do Campo e no chão da Educação de Jovens e Adultos -, tendo como objetivo de pesquisa reconhecer o envolvimento das educadoras do Projeto Tecendo a Cidadania no Campo, do polo de Flores/Formosa. Empreendemos uma metodologia de abordagem qualitativa com a realização de entrevistas semiestruturadas. A partir dos limites e desafios apontados pelas educadoras, foi possível identificar: a dificuldade em atualizar sua prática docente ao público da EJA; a falta de aproximação com uma abordagem de educação libertadora; a escassez de material didático e uma certa difículdade com a escrita e leitura por parte das educadoras. Quanto às motivações e expectativas em relação ao projeto, foram apontadas pelas educadoras os seguintes pontos: o prazer de ensinar e poder participar de momentos de troca de experiências; a vontade de uma formação; a consciência e o dever de ajudar o próximo; a necessidade de alfabetização dentro do assentamento; a busca por melhorias na realidade; a formação de cidadãos mais conscientes; a contribuição na transformação da sociedade; e a realização pessoal com a certificação dos alunos ao final do processo.
\end{abstract}

Palavras-chave: Educação do Campo, Educação de Jovens e Adultos, Emancipação. 


\title{
Prospects and analysis of the educational training process in the project with citizenship in the countryside
}

\begin{abstract}
This article has as a research problem the Rural Education and the training of the teachers who work in it through the analysis and discussion of the pedagogical work of educators participating in the National Program for Education in Agrarian Reform (PRONERA), developed in the scope of the Education of the Field and in the floor of the Education of Youths and Adults -, with the purpose of research recognizing the involvement of the educators of the Project Weaving Citizenship in the countryside, of the Flores/Formosa Polo. We undertake a methodology of qualitative approach with the accomplishment of semi structured interviews. From the limits and challenges pointed out by the educators, it was possible to identify: the difficulty in updating their teaching practice to the public of the EJA; the lack of rapprochement with an approach of liberating education; the shortage of didactic material and a certain difficulty with writing and reading by the educators. As for motivations and expectations regarding the project, the following points were pointed out by educators: the pleasure of teaching and being able to participate in moments of exchange of experiences; the desire for training; the conscience and duty to help others; the need for literacy within the settlement; the search for improvements in reality; the formation of more conscious citizens; the contribution to the transformation of society; and personal fulfillment with the certification of students at the end of the process.
\end{abstract}

Keywords: Rural Education, Youth and Adult Education, Emancipation. 


\section{Perspectivas $y$ análisis del proceso formativo de educadores en el proyecto tecendo la ciudadanía en el campo}

RESUMEN. Este artículo tiene como problema de investigación la Educación del Campo y la formación de los profesores que en ella actúan - por medio del análisis y discusión del trabajo pedagógico de educadoras participantes del Programa Nacional de Educación en la Reforma Agraria (PRONERA), que se desarrolló en el ámbito de la Educación del Campo y en el suelo de la Educación de Jóvenes y Adultos -, teniendo como objetivo de investigación reconocer el involucramiento de las educadoras del Proyecto Tejiendo la Ciudadanía en el Campo, del polo de Flores/Formosa. Se emprende una metodología de abordaje cualitativo con la realización de entrevistas semiestructuradas. A partir de los límites y desafíos señalados por las educadoras, fue posible identificar: la dificultad en actualizar su práctica docente al público de la EJA; la falta de aproximación con un enfoque de educación liberadora; la escasez de material didáctico y una cierta dificultad con la escritura y lectura por parte de las educadoras. En cuanto a las motivaciones y expectativas en relación al proyecto, fueron apuntadas por las educadoras los siguientes puntos: el placer de enseñar y poder participar de momentos de intercambio de experiencias; la voluntad de una formación; la conciencia y el deber de ayudar al prójimo; la necesidad de alfabetización dentro del asentamiento; la búsqueda de mejoras en la realidad; la formación de ciudadanos más conscientes; la contribución a la transformación de la sociedad; y la realización personal con la certificación de los alumnos al final del proceso.

Palabras clave: Educación del Campo, Educación de Jóvenes y Adultos, Emancipación. 


\section{Introdução}

Falar de uma Educação do Campo é pensar numa educação que abrange vários tipos de comunidades situadas no meio rural. Nesse ponto de vista, muitos brasileiros - tais como os quilombolas, caiçaras, lavradores, camponeses, roceiros, agricultores, indígenas, pescadores, assentados, ribeirinhos, povos da floresta, caipiras e sertanejos - possuem o direito a uma educação de qualidade, que respeite sua diversidade e que valorize seus costumes e a realidade local na qual estão inseridos.

Nessa concepção, a ideia aqui apresentada parte do pressuposto de que o processo educativo deva interferir na estrutura social em que acontece, por meio da educação de base, partindo de um exame crítico da realidade existencial dos educandos, segundo a concepção de educação libertadora de Freire (1996). No diálogo pedagógico, a alfabetização e a escolarização passam a ser compreendidas no âmbito do domínio de técnicas para escrever e ler em termos conscientes, resultando numa postura atuante do homem sobre seu contexto - aqui compreendido enquanto universo de "leitura".

A partir das lutas e da conscientização e articulação dos movimentos sociais do campo, surgem no cenário educacional os encontros $\mathrm{e}$ as Conferências Nacionais por uma Educação do Campo, ampliando o debate junto à sociedade em relação à educação e às demandas do homem do campo. Desse processo de debate, destacam-se duas importantes conquistas na área das políticas públicas, sendo as de interesse do presente trabalho: a construção do Programa Nacional de Educação na Reforma Agrária, e a aprovação das Diretrizes Operacionais para a Educação Básica nas Escolas do Campo (Brasil, 2002) no parecer $n^{\circ}$ 36/2001, cuja declaração em seu art. 2 parágrafo único indica que:

A identidade da escola do campo é definida pela sua vinculação às questões inerentes à sua realidade, ancorando-se na temporalidade e saberes próprios dos estudantes, na memória coletiva que sinaliza futuros, na rede de ciência e tecnologia disponível na sociedade e nos movimentos sociais em defesa de projetos que associem as soluções exigidas por essas questões à qualidade social da vida coletiva no país. (Parecer CNE/CEB $\mathrm{n}^{\circ} 36$, 2002).

Das batalhas enfrentadas pelos movimentos em prol da educação do campo - mais especificamente na luta pela educação dentro dos assentamentos da reforma agrária -, surge o Programa Nacional de Educação na Reforma Agrária 
(PRONERA), primeiro como Programa e mais recentemente como política pública com o compromisso de promover uma educação com qualidade que reconheça e respeite a diversidade presente na sociedade brasileira, especialmente no campo. Assim, destaca-se o protagonismo dos sujeitos do campo na construção dessa educação, vinculando-a a imagem própria do desenvolvimento e de seu papel na construção da sociedade brasileira.

$\mathrm{Na}$ Educação de Jovens e Adultos (EJA), inseridos na reforma agrária, o PRONERA (Brasil, 2012) se torna um alicerce fundamental para a transformação da realidade nos assentamentos. Tal política é justificada pelo baixo nível de escolaridade dos sujeitos que se encontram no recorte social citado, tendo como dados preocupantes o fato de cerca de $87 \%$ dos responsáveis pelas parcelas ${ }^{\mathrm{ii}}$ possuírem, no máximo, a $4^{\mathrm{a}}$ série do Ensino Fundamental, sendo que, $32 \%$ nunca frequentaram o espaço escolar (Brasil, 2005).

Apresentando um recorte mais amplo sobre o contexto do campo, a Pesquisa Nacional por Amostra de Domicílios (Pnad), de 2007, indica que o nível de escolaridade das pessoas que vivem nesse contexto social é de, em média, 4,5 anos. Em contrapartida, a população das cidades estuda cerca de 7,5 anos, dado que evidencia a discrepância entre os dois espaços.

O acompanhamento e a pesquisa sobre as ações do PRONERA podem contribuir para seu aperfeiçoamento como política pública, bem como levar-nos a compreender mais profundamente quem são os sujeitos do campo, tanto os educandos - e suas histórias - como também os educadores. Dessa forma, o presente trabalho faz parte de uma pesquisa mais ampla desenvolvida no projeto Tecendo a Cidadania no Campo, cujo objetivo é o reconhecimento dos sujeitos educadores do PRONERA, tentando traçar um retrato de suas trajetórias, possibilidades, limites, anseios e desejos na compreensão da importância de seu papel diante da realidade aqui analisada.

\section{Perspectivas da Educação do Campo}

No Brasil, ao se pensar em Educação do Campo e na formação de profissionais que nela atuam, incluindo os sujeitos formados por esses profissionais, a universalidade é algo que se encontra presente. Nessa lógica, firmam-se políticas inspiradas nos princípios urbanos - na defesa da ideologia e dos interesses da classe dominante -, sendo que essa realidade não contempla a diversidade 
existente no país. Assim, as políticas e as práticas universalistas ou generalistas apresentam-se como positivas por compreender a educação como direito de todos e dever do Estado, porém, não contemplam as especificidades da diversidade existente no âmbito nacional. Assim, disseminar o ideário da educação nos moldes urbanos - para todos - com fins de garantir o acesso à educação, de uma forma geral, perpetuará as relações de dominadores e dominados, reafirmando o espaço rural como atrasado e o espaço urbano como o modelo de civilização, sociedade, política, cultura e educação. Dessa concepção, resulta a própria negação da identidade camponesa -, ou seja, da cultura do campo - em troca das coisas urbanas, ocorrendo um deslocamento das raízes culturais com desprendimento da realidade dos povos, pois: "O paradigma urbano é a inspiração do direito à educação..." (Arroyo, 2007, p. 158). Portanto, focar nas especificidades de sujeitos de direitos universais, e em políticas afirmativas, é compreender que “... a formação específica de profissionais do campo passa a ter sentido para a garantia dos direitos e especificidades de seus povos." (Arroyo, 2007, p. 161).

Pela garantia de direitos, a Educação do Campo se constitui em espaço de disputas e de luta dos movimentos sociais, com importante papel para pensar essa conjuntura, pelo que Caldart (2012) apresenta como tríade estruturante: campoeducação-política pública. É a partir dessa tríade que podemos compreender a realidade brasileira que se expressa pela categoria Educação do Campo (Molina, 2015). Essa tríade se apresenta de forma indissociável, não sendo possível pensar a Educação do Campo apenas por uma parte, mas sim pela totalidade que a tríade apresenta.

Os movimentos sociais que lutam em defesa dos direitos dos sujeitos e da Educação do Campo defendem uma educação pública do e no campo contra todo processo de aculturação a que são submetidos esses sujeitos. Assim, enfatizase a importância de considerar o vínculo entre educação, socialização, sociabilidade, identidade, cultura, terra, território, espaço e comunidade na formação dos educadores e dos educandos do campo. A luta se posiciona contra a lógica hegemônica que impede os trabalhadores de terem acesso pleno à educação básica.

De igual maneira, a luta pela educação ocorre por meio da ocupação dos espaços, através da vida concreta dos sujeitos com suas realidades, com os conflitos humanos, com as contradições sociais, com os limites e potencialidades de um processo pedagógico. Para Caldart 
(2012) a Educação do Campo pela práxis pedagógica, ao recuperar o vínculo entre formação humana e produção material da existência, pode projetar um futuro e conceber a " ... intencionalidade educativa na direção de novos padrões de relações sociais, pelos vínculos com novas formas de produção, com o trabalho associado livre, com outros valores e compromissos políticos, com lutas sociais que enfrentam as contradições envolvidas nesses processos...". (Caldart, 2012, p. 265). Essa luta se configura também como um processo de resistência, cuja busca pela emancipação humana defende uma perspectiva que possui um projeto claro de sociedade e de concepção de educação.

Neste sentido, a concepção de educação que emerge da luta da classe trabalhadora no campo é pautada pela ideia da auto emancipação do trabalho em relação à subordinação ao capital, colocando a intencionalidade de articular educação e trabalho em um projeto emancipador. $\mathrm{O}$ movimento da Educação do Campo reconhece a articulação fundamental entre a racionalidade camponesa e o projeto educativo e adota princípios estratégicos que orientam as experiências formativas. $\mathrm{O}$ acúmulo de experiências nas lutas por direitos dos povos do campo vem demonstrando a importância estratégica do acesso à educação pública, na disputa contra hegemônica pela formação intelectual, ideológica e moral dos povos do campo. (Molina, 2015, p. 381)
Ao pensarmos na tríade estruturante da Educação do Campo e na concepção de educação a que essa se adequa, entendemos que o PRONERA - e os projetos a ele ligados - podem constituir uma possibilidade contra-hegemônica de educação e de luta pela emancipação humana. Pois, o PRONERA, de acordo com seu manual de operações, é uma política pública do Governo Federal, cujo objetivo geral é fortalecer a educação nos Projetos de Reforma Agrária, utilizando metodologias voltadas para a especificidade do campo, tendo em vista contribuir para o Desenvolvimento Rural Sustentável. Ao objetivo geral, somam-se os seguintes objetivos específicos: reduzir o analfabetismo; elevar a escolarização da população dos assentamentos; oferecer formação continuada, escolarização média e superior aos educadores; proporcionar formação técnico-profissional aos assentados; e produzir materiais didáticopedagógicos necessários para as ações educativas.

Nessa perspectiva, a metodologia dos cursos promovidos pelo PRONERA, deve respeitar: a construção de processos educativos em diferentes tempos e espaços; a interdisciplinaridade entre os diferentes conteúdos; a articulação ensino-pesquisa como fundamento para repensar a relação teórico-prática; a formação profissional 
para além dos espaços escolares; e o desenvolvimento de teorias e práticas que tenham como principal referência o campo.

A partir dos aspectos constitutivos do PRONERA, podemos pensar nos requisitos apresentados por Tonet (2005) para uma atividade educativa emancipadora. Para ele, é necessário ter um conhecimento sólido a respeito de onde se quer chegar, no caso, a emancipação humana, por meio do: “Conhecimento do processo histórico real, em suas dimensões universais e particulares, pois o processo educativo se desenvolve em um mundo historicamente determinado e em situações concretas...". (Tonet, 2005, p. 480), conhecimento do campo específico da educação, orientada pela “... articulação da atividade educativa com as lutas desenvolvidas pelas classes subalternas, especialmente com as lutas daqueles que ocupam posições decisivas na estrutura produtiva...”. (Tonet, 2005, p. 481). Diante desses aspectos, entendemos que é pela emancipação humana, fundamentada no trabalho como princípio educativo, que os homens e mulheres podem ser livres para desenvolverem suas potencialidades, tornando-se senhores e senhoras dos seus destinos.

Ao entender que a educação e os sujeitos do campo possuem especificidades, o PRONERA possibilita uma base para a consolidação de uma concepção de educação, na perspectiva apresentada, promovendo o desenvolvimento de atividades educativas por meio de projetos e parcerias com universidades e movimentos sociais.

$\mathrm{O}$ projeto aqui estudado se orienta por essa concepção, possuindo como base uma educação emancipadora, na qual, segundo Freire (1987), buscar a emancipação é pensar no contraditório, pois: "Esta condição de opressão tem o recorte de classe social, em suas obras iniciais, pois seriam estes grupos os necessitados do sentido de liberdade, autonomia e emancipação, passíveis de conquista pela práxis revolucionária destes sujeitos...”. (Silva, 2006, p. 75). Diante do exposto, a concepção de educação pela emancipação humana compreende os sujeitos pelas suas múltiplas determinações, enquanto sujeitos históricos, sociais e políticos - que sonham e lutam pelo direito a terra e à educação.

\section{Caminhos metodológicos}

A pesquisa, de abordagem qualitativa (Oliveira, 2009), está inserida no Projeto Tecendo a Cidadania no Campo - EJA, abrangendo os assentamentos do DF e Entorno. Desenvolvida pela Faculdade de Educação da Universidade de Brasília (UnB) em parceria com os movimentos 
sociais e o INCRA-SR28 - que engloba o Distrito Federal e Entorno, incluindo municípios do Nordeste de Goiás e Noroeste de Minas Gerais -, representa a quarta geração de projetos de EJA (desenvolvidos por esta parceria) financiados pelo PRONERA.

A constituição da equipe gestora foi realizada por meio da articulação com os movimentos sociais envolvidos, responsáveis pela realização das pesquisas de demanda de formação nos assentamentos e posterior seleção dos monitores e educadores.

Além dos inúmeros parceiros, o projeto teve em sua totalidade a participação de 38 assentamentos beneficiados pelo PRONERA, incluindo 600 (seiscentos) jovens e adultos dos assentamentos em processo de alfabetização e escolarização até o $1^{\circ}$ ciclo do Ensino Fundamental; 50 (cinquenta) educadores/as dos assentamentos que fazem parte de projetos da Reforma Agrária; 4 (quatro) coordenadores locais dos movimentos sociais que lutam pela reforma agrária no Distrito Federal e Entorno; 5 (cinco) estudantes do curso de Pedagogia da Universidade de Brasília que trabalharam como monitores no suporte e acompanhamento pedagógico das salas de aulas dos assentamentos; 2 (duas) professoras da Universidade de Brasília que atuaram como coordenadoras pedagógicas; e 2 (dois) técnicos administrativos que deram suporte ao projeto.

Para o presente artigo, nos deteremos aos polos de Flores e Formosa, ambos situados no Estado de Goiás, os quais abrangeram a participação de 12 (doze) assentamentos. Destes, tivemos a participação na pesquisa de 9 (nove) educadoras que atuaram nas regiões citadas.

Diante do exposto, elegemos como instrumento metodológico a entrevista semiestruturada, elaborada a partir da participação no projeto e no acompanhamento das educadoras. A respeito do instrumento de coleta de dados escolhido, concordamos com a perspectiva de Szymanski (2002), ao indicar que, ao “... partimos da constatação de que a entrevista face a face é fundamentalmente uma situação de interação humana, em que estão em jogo as percepções do outro e de si, expectativas, sentimentos, preconceitos e interpretações para os protagonistas: entrevistador e entrevistado." (Szymanski, 2002, p. 12).

Após o estudo da temática e da etapa da observação e do acompanhamento do projeto, realizamos as transcrições dos dados obtidos, e por meio delas começamos a efetuar as análises que nos 
possibilitaram identificar elementos que contribuíram para o alcance do objetivo proposto. A seguir, apresentaremos a compreensão sobre as múltiplas determinações que caracterizam as educadoras. Importante ressaltar, que para preservar a identidade das educadoras utilizaremos nomes fictícios de mulheres que são símbolo de luta na história.

\section{Diálogo com as educadoras: emancipação e educação}

Com o intuito de melhor conhecer a realidade educacional que permeia $o$ PRONERA, tomamos como alicerce para nosso estudo as educadoras que participaram do projeto Tecendo a Cidadania no Campo, vinculado à Universidade de Brasília, à Superintendência Regional 28 do INCRA, aos sindicatos de trabalhadores rurais por via da Federação dos Trabalhadores na Agricultura do Distrito Federal e Entorno (FETADFE) e aos movimentos sociais do campo com o Movimento dos Sem Terras (MST) e o Movimento de Apoio ao Trabalhador Rural (MATR).

Antes de apresentarmos o perfil das participantes da pesquisa, cabe ressaltar que o projeto, do qual as educadoras fizeram parte, foi uma ação do PRONERA que se propôs à alfabetização e à escolarização dos sujeitos do campo até o quinto ano do Ensino Fundamental. A atuação como educador no projeto pressupôs uma indicação do movimento social à frente do assentamento, bem como o requisito mínimo de possuir o Ensino Médio completo.

A partir do recorte analisado, apontamos o primeiro dado significante em relação ao gênero, pois todas as educadoras participantes são do sexo feminino. Esses dados não divergem do contexto geral do projeto, pois a presença dos homens no exercício do papel de educador é quase inexpressiva, podendo ser explicada pelos trabalhos empenhados no campo, e pelo reflexo de dados das pesquisas que apontam que o tempo de escolaridade das mulheres que vivem no campo é maior que o dos homens. Além disso, dentro da questão de gênero, Cruz (2012) aponta que o processo de feminização no exercício da docência, com a presença expressiva da mulher, é um elemento sócio-histórico que marca a constituição da profissão docente, principalmente nos anos iniciais. Essa marca de feminização no magistério tem perdurado ao longo dos tempos, apresentando formas diversas dentro da realidade das mulheres. Esse processo histórico também se configura dentro do imaginário das pessoas ao pensarem a alfabetização, ficando claro para nós ao 
percebemos que apenas mulheres foram indicadas pelos movimentos sociais.

Em relação à idade, é notório que a maioria das educadoras possui menos de 50 anos, apresentando um contraste interessante em relação aos educandos e aos assentados, em sua grande maioria, compreendendo um universo de pessoas com idade superior à das educadoras.

No tocante à origem dessas educadoras, vale ressaltar que $56 \%$ são de procedência nordestina, enquanto o restante é oriundo da própria região Centro-Oeste. O dado apresentado se torna interessante, pois muitos dos educandos possuem a mesma origem das educadoras, fato que pode possibilitar uma prática pedagógica mais próxima da experiência de vida dos envolvidos no processo educativo, fazendo do elo regional uma categoria a ser explorada nos debates em sala de aula.

Outro ponto importante se refere à formação dessas educadoras. A maioria conta, apenas, com a formação oriunda da educação básica como aporte teórico e metodológico para o trabalho na sala de aula, contribuindo, em muitos casos, para a reprodução das estruturas tradicionais de alfabetização e escolarização. Também são perceptíveis as dificuldades em relação à norma culta da língua durante a escrita, por exemplo, equívocos de acentuação, esquecimento de pontuações, uso inadequado de palavras no contexto singular/plural, trocas frequentes de letras “ç" por "s" por "z", entre outros.

Diante da situação descrita, o projeto buscou romper com as estruturas tradicionais de ensino numa perspectiva de educação crítico-emancipadora, através da qual os participantes buscam um processo de emancipação possível de alcançar por meio dos estudos, à medida que se libertam das estruturas que os oprimem, levando-os simultaneamente a reverem os conteúdos e os processos pedagógicos que vivenciaram na escola para fins de compreenderem e superarem as dificuldades geradas pelas práticas tradicionais, e por meio delas se emanciparem. Em muitos casos, essa opressão foi gerada por não serem protagonistas das suas histórias, tanto pela falta da leitura como da escrita.

No contexto da pesquisa, a experiência profissional das educadoras tornou-se uma questão de grande relevância, pois $67 \%$ delas já tiveram algum contato com a docência anteriormente, o que as deixa um pouco mais tranquilas em relação ao cotidiano de sala de aula. Porém, essas experiências trazem consigo bagagens de uma educação não condizente com a Educação de Jovens e Adultos, carregadas com práticas 
destinadas às crianças. Fato evidenciado no seguinte relato:

Eu trabalhei cinco anos em sala de aula, mas foi com crianças. $\mathrm{Eu}$ trabalhava com quatro salas que eram numa fazenda, só que a gente vê que o ensino era diferente. Essa experiência agora está sendo diferente pra mim. No começo, eu não comecei assim nesse trabalho, porque eu entrei igual eu fazia antes, pegava trabalhando o alfabeto do inicio igual o pessoal queria, do jeito igual que os filhos aprenderam assim e assim, com "A" de abelha, "B" de bola e por aí vai. Comecei assim. (Educadora Dandara).

É possível perceber na fala da Educadora "Dandara" o processo de infantilização da EJA por meio dos professores/educadores, dos livros didáticos e da estrutura posta. Isso se dá pelo fato dos documentos oficiais terem incorporado a EJA de forma tardia, acarretando um não amadurecimento e planejamento para essa implementação. Dessa forma, o que fizeram foi a adaptação das estruturas e materiais já existentes, sem levar em consideração as especificidades do público. Assim, “... o Ensino Supletivo, ao depender fundamentalmente de todas as instalações e de pessoal administrativo e docente do ensino primário de crianças, definiu-se como uma réplica do ensino infantil ...”. (Moura, 2009, p. 51). Conforme apontado pela Educadora "Dandara", ainda podemos perceber essa problemática atualmente, pois ao se verem na realidade da sala de aula as educadoras tendem a utilizar o que aprenderam em suas experiências anteriores, prática que, muitas vezes, não cabe ao ensino da EJA.

Dessa realidade, advém o que presenciamos - o ensino da EJA realizado com base em atividades infantis, sem levar em consideração as características específicas da clientela jovem, adulta. Temos, então, um ensino infantilizado para adultos, o que é, em nosso ponto de vista, problemático. (Maraschin, 2006, p. 98).

É importante ressaltar que o fazer pedagógico das educadoras perpassa as múltiplas determinações que as constituem, pelos contextos aos quais se inserem, e pelos processos sociais, históricos e políticos que influenciaram e influenciam sua formação e consequente atuação.

Contudo, também é importante ressaltar que o projeto, numa perspectiva de educação crítica-emancipadora, dialógica e transformadora (com base em Freire), possibilitou para essas educadoras uma constante reflexão de suas práticas, a partir das problematizações e discussões nos grupos de formação. Assim, ao pensar no processo de emancipação, essas educadoras puderam - a partir de uma concepção prática que visa uma relação teoria e prática com vistas à transformação social -, repensar sua atuação e constituir uma práxis (Vazquez, 2011). Dessa forma, pode-se observar ao longo do processo 
como as bases de ensino - antes tradicionais - foram sendo discutidas e repensadas junto às educadoras, ocasionando um processo emancipador e mais crítico do seu fazer pedagógico, com a transformação dos educandos e das educadoras ao mesmo tempo.

Nesse processo de emancipação que as educadoras vivenciaram, pode-se perceber também o interesse em cursar o ensino superior, sendo a Pedagogia o polo aglutinador desses interesses. Conforme algumas educadoras relataram, a participação no projeto reativou o desejo latente por essa formação, evidenciado na seguinte fala:

Meu sonho era fazer Pedagogia, e esse sonho nunca parecia que ia tornar-se realidade. Me desmotivei com o passar dos anos e hoje participar do projeto me deixou motivada novamente pra correr atrás de meus sonhos. Ver meus alunos com mais de 60 anos e animados pra estudar me motiva a correr atrás de fazer minha faculdade. (Educadora Margarida).

Em relação ao contato com a política pública do PRONERA, torna-se evidente a importância dos movimentos, cujos sindicatos, associações e mobilizações conseguem alcançar e disseminar informações nos mais distantes rincões do país, tendo como missão percorrer longas e precárias estradas para efetivar uma comunicação, pois, muitas vezes, não existe a infraestrutura de luz e telefone. No âmbito de formação dessas educadoras, destaca-se a participação em cursos de formação e extensão da Universidade de Brasília e nas atividades desenvolvidas pelo INCRA.

O Projeto Tecendo a Cidadania no Campo se opõe a uma formação de professores/educadores no viés utilitarista, pois defende como direcionamento para a formação das educadoras os pressupostos apresentados por Silva (2011), os quais indicam uma educação críticoemancipadora que entende a realidade como contraditória e dialética. Essa concepção “... busca construir uma indissociabilidade de teoria e prática na práxis. Tal concepção entende a formação como atividade humana que transforma o mundo natural e social para fazer dele um mundo humano...". (Silva, 2011, p. 22). Dessa forma, é possível constituir uma práxis transformadora através da relação dos sujeitos - tanto as educadoras quanto os educandos -, com a teoria e a prática, o conhecimento e a transformação.

Portanto, é a partir de uma concepção de formação e atuação pela práxis que os participantes do projeto podem estabelecer um processo de ação e reflexão, realizando uma prática social orientada e planejada de forma bem definida. O processo de formação implica 
na relação entre experiência e conhecimento, visto que, para Reis (1995) “... o ato de conhecer é um caminho privilegiado para a compreensão da realidade, conhecer, em si, não transforma a realidade, transforma a realidade somente a conversão do conhecimento em ação...". (Reis, 1995, p. 51). Nesse sentido, por meio do movimento dialético - entre a conversão do conhecimento em ação transformadora, e ação transformadora em conhecimento -, pode-se constituir uma práxis que transforme a realidade e os sujeitos.

No tocante a identidade com $\mathrm{o}$ campo, as educadoras se dizem felizes por realizarem o sonho de estarem mais próximas da natureza, segundo elas, um lugar que propicia maior tranquilidade e melhores condições de vida.

Outro fato de destaque levantado foi a motivação dessas educadoras em participar do projeto. Inúmeros motivos surgiram, entre eles: o prazer de ensinar e poder participar de momentos de troca de experiências; a vontade da formação e reciclagem como educadora; a consciência e o dever de ajudar o próximo; a necessidade de alfabetização dentro do assentamento; e a compreensão do porquê, após terem vivido toda uma vida, essas pessoas ainda buscarem por educação.
Sobre o entendimento do que é educação apareceram respostas que trazem perspectivas de ser aquilo que vem do berço, e respostas mais conscientes que retratam a politização do educador ao mencionar ser a troca de experiências - nas dimensões do saber, do ensinar e do aprender com o outro na conquista de novas ideias -, proporcionando liberdade, mudanças, dignidade e respeito.

Dentre as expectativas que elas possuem, em relação ao trabalho no projeto, estão as melhorias para a realidade do assentamento; a formação de cidadãos mais conscientes; a contribuição na transformação da sociedade; e a realização pessoal com a certificação dos alunos ao final do processo.

Nas entrevistas, também foram mencionados pontos que elas gostam e que não gostam dentro do projeto. Na visão de muitas, os encontros de formação são um dos pontos mais positivos, tanto pela capacitação realizada quanto pelas trocas de ideias com as colegas e atividades realizadas durante o evento. Nos relatos das educadoras ficou nítida a importância aferida aos encontros de formação, conforme indicado nos relatos abaixo.

$\mathrm{Eu}$ tinha muita insegurança, pensei até em entregar a sala, eu tinha medo de passar alguma coisa errada pra eles porque depois como é que eles iam ficar. Eu não tinha um apoio determinado pra que se eu errasse 
pudesse me ajudar. Mas agora eu já to bem mais confiante. Eu tinha falado várias vezes em desistir, no primeiro encontro eu vim determinada pra entregar a sala, mas com as atividades e a formação que tivemos eu compreendi muito do que tava acontecendo na minha sala. Hoje eu me sinto muito mais capacitada e segura. (Educadora Anita).

A cada momento que passa eu vejo que a gente vai aprendendo um pouco mais e quando você se sente com medo de tá fazendo errado e que não vai conseguir, é a hora que vocês nos chamam pra cá pra mostrar que o suporte continua e que vocês não esqueceram da gente. (Educadora Dorothy).

Aqui eu aprendi pela primeira vez, como trabalhar realmente o PRONERA. Porque até então o que eu tava passando pra eles é o que a gente ensina pra criança com desenhos e coisas desses tipos. Graças a Deus depois que eu vim pro encontro eu entendi um pouco como as coisas funcionam. (Educadora Roseli).

Para elas, os encontros de formação se constituíram em espaços de ressignificação dos processos formativos praticados, permitindo a elaboração de elementos fortalecedores da práxis educacional, além de permitir a aquisição de conhecimentos necessários para a emancipação e transformação da realidade vivida. Nessa experiência, foi possível repensar as contradições da realidade e buscar mediações que permitissem a superação das mesmas.

$\mathrm{Na}$ autoavaliação do caminho percorrido (desde o começo do projeto) com o foco no próprio desenvolvimento -, muitas educadoras expuseram a superação dos desafios surgidos no cotidiano de suas salas de aula, e as mudanças de concepções que sofreram com o andamento das aulas, dos cursos de formação e dos diálogos entre os envolvidos no projeto. $\mathrm{O}$ sentimento colocado pelo coletivo de educadoras é muito próximo ao que pode ser visto nos relatos abaixo:

A cada dia que eu amanheço eu vejo que aprendi alguma coisa diferente, me sinto renovada. Vejo que não sou mais aquela pessoa de algum tempo atrás. (Educadora Dandara).

$\mathrm{Na}$ minha mudança eu sinto que a auto confiança começou a me ajudar dentro de sala, e depois da visita eu realmente compreendi a questão do planejamento. Percebi como devo me programar pra tá em sala, não simplesmente fazer alguma coisa porque eu tenho que fazer, mas sim, ter alguma intenção com o que estou fazendo pra conseguir alcançar meus objetivos, deixando as coisas claras pra mim, porque se não estiverem pra mim imagina pros meus alunos. (Educadora Margarida).

Minha desenvoltura em sala de aula melhorou bastante, fiquei mais segura com o passar do tempo. No inicio eu tinha muito medo de alguém perguntar alguma coisa e eu não saber. Hoje tenho a liberdade de não saber e falar que vou procurar. (Educadora Maria).

Pude perceber que ganhei experiência, e dentro da sala de aula o que sinto na minha sala é o reconhecimento por um saber que a gente tá adquirindo, que a gente não guarda, mas transmite. (Educadora Ivone).

Assim, pode-se perceber que a concepção de educação libertadora e de 
emancipação humana vai sendo incorporada ao processo educativo, pela práxis, na relação diferenciada que se estabelece entre conhecimento e realidade concreta. Segundo Silva (2006), “... a educação libertadora estimula o ser humano a se mobilizar ou a se organizar para adquirir poder. É uma forma de comunicação que provoca o outro a participar, incluindo-o na busca ativa por sua autonomia.”. Essa perspectiva foi evidenciada na fala das educadoras acima, quando elas indicam romper com o medo e caminhar em direção à autonomia e à emancipação humana.

No processo formativo, as educadoras também relatam a importância do apoio proporcionado pelo diálogo entre elas, por meio das visitas feitas para o acompanhamento pedagógico, conforme pode ser observado no seguinte relato:

Tudo que a gente começa a gente se sente fraco, no inicio eu pensei que não ia conseguir. Antes eu não conhecia o pessoal aqui fora e no começo das aulas eu tava envolvida nas eleições, então não tive o apoio da associação onde o presidente me dizia que aquilo ali ia parar, que era só fogo de palha. Me senti muito insegura, porque aqueles alunos estavam ali confiando em mim e eu não tinha em quem confiar. Além disso, eu entrei no projeto um pouco depois e fiquei sabendo que já tinham tido outras reuniões, aí que eu me senti mais perdida ainda. Mas graças a Deus as meninas foram muito parceiras e me ensinaram o que fazer e como fazer. E com a visita de vocês as coisas começaram a clarear mais ainda. Vi que realmente temos com quem contar. (Educadora Roseli).

Para Freire (1987) o diálogo é uma ação libertadora permanente, e para tanto necessária para a emancipação dos sujeitos. Em relação à proposta metodológica Freireana, muitas educadoras sentem a dificuldades de colocá-la em prática, porém, a partir das experiências dialógicas trocadas nos encontros de formação e nas intervenções realizadas pelos monitores durante as visitas, elas começam a perceber o sentido.. Assim, devido à proposta de trazer para a realidade o conhecimento que desejam construir, elas compreendem ser uma forma de alcançar, de modo mais rápido, os objetivos indicados. Em seu relato, a Educadora Rosely indica as mudanças que ocorreram na postura de seus alunos após adotar a proposta freireana em suas ações.

Quando eu trabalhava no método tradicional as aulas eram monótonas, eu falava pra eles fazerem e eles faziam, se eu não falasse nada eles ficavam lá e não fazia nada, afinal você não falou. Ali era assim, um mandou o outro obedeceu. Não tinham o interesse de buscar nada. O tradicional era aqui, ali e ponto final. No caso agora do que eu aprendi com as ideias de Paulo Freire, eles começaram a ter curiosidade. Eles pedem, buscam, leem, no outro dia quando eu chego, eles já trouxeram um monte de outras coisas. O método fez com que eles procurassem o que eles querem. (Educadora Roseli). 
Nas diferenças apontadas, entre $\mathrm{o}$ método tradicional e a proposta de educação ancorada em Paulo Freire, encontra-se a concepção de que o ensino transcende o conteúdo e a forma, atingindo algo há mais na vida dos educandos e educadores que participam do processo. Assim, nas falas das educadoras, fica evidente a emancipação ocorrida com a formação política que ocorre dentro das salas de aula do projeto, conforme pode ser observado no relato abaixo.

Eu não posso esperar pelo INCRA pra dar aulas pros meus alunos, não posso depender da UnB pra fazer alguma coisa. $\mathrm{O}$ ponto que eu cheguei foi conquistado, agora eu tenho que segurar aquilo ali. Independente se eu vou ganhar ou se vou perder, eu não posso deixar meus alunos a ver navios. Quer dizer, você nada, nada e nada e vai morrer na praia? Eu não posso fazer uma coisa dessas. O que tiver ao meu alcance eu vou fazer. (Educadora Dorothy).

Participando do projeto eu comecei a ver que ler e escrever é bem mais do que você colocar no papel. Eu passo pros meus alunos que as pedras no caminho não são motivos pra gente desanimar, é como no caminho das águas, se ela não consegue passar num canto ela vai por outro e ninguém para. (Educadora Anita).

No que concerne às dificuldades encontradas com a abordagem Freireana, foram elencadas a falta de conhecimento prévio com a proposta, a falta de materiais didáticos para estudo da mesma, o não contato durante a vida escolar, e a exigência de uma postura em sala de aula que não se constrói rapidamente.

Nas entrevistas também surgiram depoimentos, trazendo à tona sua visão em relação ao que motiva os educandos a estudarem, e um pouco da transformação das relações no assentamento.

Eu vejo a história deles muito parecida com a minha. Eu parei de estudar em 78 , na $4^{\text {a }}$ serie e vim voltar em 93. Nesse tempo eu percebi que me fazia falta e é isso que eu vejo neles, que eles estão estudando não porque é uma obrigação, mas porque faz falta, que eles têm necessidade e dessa necessidade vem à força de vontade deles pra tá ali estudando. (Educadora Margarida).

Ter sala de aula no assentamento trouxe uma aproximação do povo, porque até eu mesma não tinha contato com muita gente lá, era cada um na sua parcela, hoje depois que começaram as aulas conhecemos um pouco mais de quem tá ali perto da gente, de como podemos nos ajudar. (Educadora Anita).

Segundo as educadoras, a proposta de educação libertadora instaurada nesse processo é a forma mais coerente e adequada de se atingir os objetivos do projeto e seus anseios pessoais, pois tratase de uma educação presente tanto nas salas de aulas como em todos os outros momentos da vida. Portanto, não se restringe ao conhecimento, ao pensamento crítico ou à sua manipulação, também não se restringe aos espaços formais de ensino, visto que, possibilita que o processo de formação venha aflorar da sistematização 
das trocas de experiências e vivências, possibilitando que os significados de conhecimento surjam de uma construção coletiva.

No que ficou implícito ao processo educativo, conhecer um pouco mais das educadoras elencou uma educação que vislumbra ultrapassar os muros da educação formal, na qual muitas têm a sala de aula como espaço de pesquisa no qual se torna possível sistematizar de forma crítica o conhecimento para utilizá-lo na transformação da comunidade.

Do ponto de vista do investigador importa, na análise que faz no processo da investigação, detectar o ponto de partida dos homens no seu modo de visualizar a objetividade, verificando se, durante o processo, se observou ou não alguma transformação no seu modo de perceber a realidade. (Freire, 1987, p. 99).

Para Gramsci (2000), através da emancipação, a educação pode contribuir para a transformação de todos os sujeitos, para que os mesmos possam ser autônomos em seu conhecimento. Para isso, a formação do homem precisa ser integral e política, a fim de possibilitar um conhecimento crítico, criativo e dialético, opondo-se à concepção tradicional de ensino, a qual não atende às especificidades da EJA e da Educação do Campo. Portanto, é através da práxis emancipadora que os sujeitos poderão alcançar uma consciência crítica capaz de transformar suas realidades.

\section{Considerações finais}

A partir das reflexões sobre a Educação do Campo, a Educação de Jovens e Adultos e o Programa Nacional de Educação na Reforma Agrária pode-se melhor compreender a articulação e a mobilização política dos movimentos sociais em prol de seus direitos, na luta pela garantia de uma educação de qualidade - condizente com sua realidade e com a crítica sobre a sociedade -, por meio de práticas pedagógicas que não destoem do que o espaço reivindicado necessita.

Nessa proposta, torna-se nítida a preocupação com uma educação que proporcione um aprendizado que seja realmente útil aos educandos, sendo fundamentado e articulado no contexto real da vida desses sujeitos. Ao ter a reflexão e a ação como parceiras que caminham juntas, os educandos são colocados como sujeitos de transformação na sociedade, e não como meros receptores e reprodutores de conhecimentos sem qualquer importância para suas vidas.

Assim como na proposta educativa do Projeto Tecendo a Cidadania no Campo - e em muitos outros pelo país afora -, desconstruir pensamentos e barreiras que 
se julgam difíceis na implementação de uma proposta educativa traz o sentimento da responsabilidade social e humana que cada indivíduo deveria ter com o próximo, no exercício de uma pedagogia libertadora com caráter político na busca pela transformação da sociedade.

Perceber o envolvimento de educandos e educadoras - que juntos descobrem um novo universo antes inimaginável -, reafirma a educação como alicerce para várias conquistas do dia-adia, tais como: uma mera assinatura num documento; a autonomia de pegar uma condução sozinho; conseguir tirar a tão sonhada carteira de habilitação; ler uma notícia e poder registrar suas histórias sem o auxílio de terceiros. Para muitos, que desde crianças tiveram a oportunidade de ingressar num processo educativo que lhes proporcionou tais instrumentos, pode parecer algo muito singelo, porém, a emancipação do mundo possibilitada pela aquisição do domínio da forma escrita é imensurável para aqueles que aspiram novos horizontes.

Como não se entusiasmar com a contaminação eminente do desejo de aprender mais? Um desejo visto nos educandos e consequentemente nas educadoras, cujo envolvimento com o projeto sugere acender uma chama na ambição de retorno aos estudos.
Conhecer esses sujeitos e vivenciar essas experiências junto a eles é algo que possui grande magnitude no âmbito da formação coletiva dos envolvidos, na qual, indiretamente, se constrói uma rede de ensino e aprendizagem a partir do envolvimento mútuo entre educandos e educadoras, por meio da qual todos ensinam e aprendem simultaneamente.

Desse artigo, fica o desejo de continuar desbravando esse universo único e tão peculiar do meio rural, dos sujeitos do campo, da Educação do Campo e das lutas que circundam essa realidade, e também de ter a oportunidade de conhecer melhor como se constituem as relações desse ambiente, saber qual a melhor forma de contribuir com os objetivos dos sujeitos locais, e como de fato trilhar e construir uma educação que seja emancipadora e libertária.

\section{Referências}

Arroyo, M. G. (2007). Políticas de formação de educadores (as) do campo. Cad. Cedes, 27(72), 157-176.

Brasil. (2002). Diretrizes Operacionais para a Educação Básica nas Escolas do Campo. Resolução CEB/ CNE. Brasília DF: Ministério da Educação.

Brasil. (2005). Pesquisa Nacional da Educação na Reforma Agrária (PNERA). Brasília - DF: Ministério do Desenvolvimento Agrário/Ministério da Educação. 
Brasil. (2012). Programa Nacional de Educação na Reforma Agrária PRONERA: Manual de operações. Brasília - DF: Ministério do Desenvolvimento Agrário. Recuperado de: http://www.incra.gov.br/sites/default/files/ manual_de_operacoes_do_pronera_2012.p $\underline{\mathrm{df}}$

Caldart, R. S. (2012). Educação do Campo. In Caldart, R. S., Pereira, I. B., Alentejano P., \& Frigotto, G. (Orgs.). Dicionário da Educação do Campo (pp. 259-267). Rio de Janeiro/São Paulo: EPSJV/Expressão Popular.

Cruz, S. P. S. (2012). A construção da profissionalidade polivalente na docência nos anos iniciais do ensino fundamental: as práticas e os sentidos atribuídos às práticas por professoras da Rede Municipal de Ensino do Recife (Tese de Doutorado). Universidade Federal de Pernambuco, Recife.

Freire, P. (1987). Pedagogia do Oprimido. Rio de Janeiro: Paz e Terra.

Freire, P. (1996). Pedagogia da Autonomia: saberes necessários à prática educativa. São Paulo: Paz e Terra.

Gramsci, A. (2000). Cadernos do cárcere. Rio de Janeiro: Civilização Brasileira.

Maraschin, M. S. (2006). Formação de professores e desenvolvimento profissional na Educação de Jovens e Adultos (Dissertação de Mestrado). Universidade Federal de Santa Maria, Santa Maria.

Molina, M. C. (2015). A Educação do Campo e o enfrentamento das tendências das atuais políticas públicas. Educação em Perspectiva, 6(2), 378-400.

Moura, T. M. M. (2009). Formação de educadores de jovens e adultos: realidade, desafios e perspectivas atuais. Práxis Educacional, 5(7), 45-72.
Oliveira, C. L. (2009). Um apanhado teórico-conceitual sobre a pesquisa qualitativa: tipos, técnicas e características. Revista Travessias, 2(3), 1-16. Recuperado de: http://erevista.unioeste.br/index.php/travessias/arti cle/view/3122/2459

Parecer CNE/CEB $\mathrm{n}^{\circ} 36$ (2002, 3 de março). (2002). Recuperado de: http://portal.mec.gov.br/index.php?option= com_docman\&view=download \&alias $=119$ 89-pceb036-01pdf\&category_slug=novembro-2012pdf \&Itemid $=30192$

Reis, R. H. (1995). O currículo enquanto instrumento viabilizador da articulaçãoensino-pesquisa-extensão. Caderno de Extensão Universitária, 4.

Silva, K. A. C. P. C. (2011). A formação de professores na perspectiva críticoemancipadora. Linhas Críticas, 17(32), 1331.

Silva, M. S. (2006). Educação da raiz à flor: produção pedagógica dos movimentos sociais e a escola do campo. In Molina, M. C. (Org.). Educação do Campo e pesquisa: questões para reflexão (pp. 60-93). Brasília: Ministério do Desenvolvimento Agrário.60-93

Szymanski, H. (2002). A entrevista na pesquisa em educação: a prática reflexiva. Brasília: Editora Plano.

Tonet, I. (2005). Educar para a cidadania ou para a liberdade? Perspectiva, 23(2), 469-484.

Vazquez, A. S. (2011). Filosofia da Práxis. São Paulo/Buenos Aires: Expressão Popular.

\footnotetext{
i Texto adaptado de dois textos. O primeiro, um trabalho de conclusão de curso em Pedagogia pela
} 
Universidade de Brasília, em 2013; o segundo, um artigo publicado nos Anais da $13^{\mathrm{a}}$ reunião Regional da Anped Centro-Oeste, Brasília - DF, 2016.

ii Por parcela compreende-se o fragmento do território do assentamento destinado a cada família assentada.

\section{Informações do artigo / Article Information}

Recebido em : 30/05/2018

Aprovado em: 19/06/2018

Publicado em: 23/12/2018

Received on May 30th, 2018

Accepted on June 19th, 2018

Published on December 23th, 2018

Contribuições no artigo: Alisson Silva da Costa foi responsável pela elaboração, análise e interpretação dos dados, escrita e revisão do conteúdo, com participação direta de Cláudia Valéria de Assis Dansa e Nathália Barros Ramos em todas as etapas do trabalho. Todos os autores foram responsáveis pela versão final publicada.

Author Contributions: Alisson Silva da Costa was responsible for the preparation, analysis and interpretation of the data, writing and review of the content, with the direct participation of Cláudia Valéria de Assis Dansa and Nathália Barros Ramos in all stages of the work. All authors are responsible for the final published version.

Conflitos de interesse: Os autores declararam não haver nenhum conflito de interesse referente a este artigo.

Conflict of Interest: None reported.

Orcid

Alisson Silva da Costa

iD http://orcid.org/0000-0002-6456-1435

Cláudia Valéria de Assis Dansa

(iD) http://orcid.org/0000-0002-6130-6965

Nathália Barros Ramos

(iD) http://orcid.org/0000-0003-2643-1565

\section{Como citar este artigo / How to cite this article}

\section{APA}

Costa, A. S., Dansa, C. V. A., \& Ramos, N. B. (2018). Perspectivas e análises do processo formativo de educadoras no projeto tecendo a cidadania no campo. Rev. Bras. Educ. Camp., 3(4), 1372-1392. DOI: http://dx.doi.org/10.20873/uft.2525-4863.2018v3n4p1372

ABNT

COSTA, A. S.; DANSA, C. V. A.; RAMOS, N. B. Perspectivas e análises do processo formativo de educadoras no projeto tecendo a cidadania no campo. Rev. Bras. Educ. Camp., Tocantinópolis, v. 3, n. 4, set./dez., p. 1372-1392, 2018. DOI: http://dx.doi.org/10.20873/uft.2525-4863.2018v3n4p1372 